\title{
Monitoring newt communities in urban area using eDNA metabarcoding
}

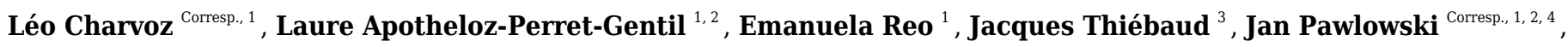 \\ Loï Pillet ${ }^{1}$ \\ 1 Department of Genetics and Evolution, University of Geneva, Geneva, Geneva, Switzerland \\ 2 ID-Gene ecodiagnostics, Campus Biotech Innovation Park,, Geneva, Geneva, Switzerland \\ 3 KARCH-GE (Swiss Coordination Center for the Protection of Amphibians and Reptiles) - Geneva regional branch, 1200, Switzerland, Geneva, Geneva, \\ Switzerland \\ 4 Polish Academy of Sciences, Institute of Oceanology, , 81-712 Sopot, Poland, Sopot, Pomerania, Poland \\ Corresponding Authors: Léo Charvoz, Jan Pawlowski \\ Email address: leo.charvoz@etu.unige.ch, Jan.Pawlowski@unige.ch
}

Newts are amphibians commonly present in small ponds or garden pools in urban areas. They are protected in many countries and their presence is monitored through visual observation and/or trapping. However, newts are not easy to spot as they are small, elusive and often hidden at the bottom of water bodies. In recent years, environmental DNA (eDNA) has become a popular tool for detecting newts, with a focus on individual species using qPCR assays. Here, we assess the effectiveness of eDNA metabarcoding compared to conventional visual surveys of newt diversity in 45 ponds within urban areas of Geneva canton, Switzerland. We designed newt-specific mitochondrial 16S rRNA primers, which assign the majority of amplicons to newts, and were able to detect four species known to be present in the region, including the invasive subspecies Lissotriton vulgaris meridionalis, native to the Italian peninsula, that has been introduced in the Geneva area recently. The obtained eDNA results were congruent overall with conventional surveys, confirming the morphological observations in the majority of cases (67\%). In $25 \%$ of cases, a species was only detected genetically, while in $8 \%$ of cases, the observations were not supported by eDNA metabarcoding. Our study confirms the usefulness of eDNA metabarcoding as a tool for the effective and non-invasive monitoring of newt community and suggests its broader use for the survey of newt diversity in urban area at larger scales. 
1 Monitoring newt communities in urban area using eDNA metabarcoding

4 Charvoz, L. ${ }^{1}$, Apothéloz-Perret-Gentil, L. ${ }^{1,2}$, Reo, E. ${ }^{1}$,Thiébaud, J. ${ }^{3}$, Pawlowski J. 1,2,4

$6{ }^{1}$ Department of Genetics and Evolution, University of Geneva, 1211 Geneva,

7 Switzerland

$8 \quad 2$ ID-Gene ecodiagnostics, 1228-Plan-les-Ouates, Switzerland

$9 \quad{ }^{3} \mathrm{KARCH}-\mathrm{GE}$ (Swiss Coordination Center for the Protection of Amphibians and

10 Reptiles) - Geneva regional branch, 1200 Geneva, Switzerland

$11{ }^{4}$ Institute of Oceanology, Polish Academy of Sciences, 81-712 Sopot, Poland

14 Corresponding Author:

15 Charvoz Léo

16 Chemin de Grange Collomb 52, Carouge, Geneva, 1227, Switzerland

17 Email address: leo.charvoz@etu.unige.ch 


\section{Abstract}

27 Newts are amphibians commonly present in small ponds or garden pools in urban 28 areas. They are protected in many countries and their presence is monitored through visual observation and/or trapping. However, newts are not easy to spot as they are small, elusive and often hidden at the bottom of water bodies. In recent years, environmental DNA (eDNA) has become a popular tool for detecting newts, with a focus on individual species using qPCR assays. Here, we assess the effectiveness of eDNA metabarcoding compared to conventional visual surveys of newt diversity in 45 ponds within urban areas of Geneva canton, Switzerland. We designed newt-specific mitochondrial 16S rRNA primers, which assign the majority of amplicons to newts, and were able to detect four species known to be present in the region, including the invasive subspecies Lissotriton vulgaris meridionalis, native to the Italian peninsula, that has been introduced in the Geneva area recently. The obtained eDNA results were congruent overall with conventional surveys, confirming the morphological observations in the majority of cases (67\%). In $25 \%$ of cases, a species was only detected genetically, while in $8 \%$ of cases, the observations were not supported by eDNA metabarcoding. Our study confirms the usefulness of eDNA metabarcoding as a tool for the effective and non-invasive monitoring of newt community, and suggests its broader use for the survey of newt diversity in urban area at larger scales.

\section{Introduction}


52 According to the International Union for Conservation of Nature (IUCN), almost $41 \%$ of

53 all amphibian species are threatened with extinction while $70 \%$ are drastically declining

54 in numbers (IUCN, Hayes et al. 2010). The main threats faced by amphibians are

55 habitat modification and destruction, over-exploitation of environmental resources,

56 water and soil pollution (Rouse et al. 1999) climate modifications and the impact of

57 invasive alien species (Clavero \& Garcia-Berthou 2005), as well as diseases (such as chytridiomycosis) (Van Rooij et al. 2015). Among amphibians, the newts (subfamily Pleuordelinae) seem less affected by chytridiomycosis, but their conservation status is of constant concern due to the destruction and pollution of their aquatic habitats. Although only two European species of newt are on the UICN Red List (Temple \& Cox 2009), most are protected nationally (e.g., the Great crested newt (Triturus cristatus) in the UK (English Nature 2001, Bormpoudakis et al. 2016 2 d other European countries (Edgar et al. 2006)).

Among the five species of newts present in Switzerland, only the Alpine newt (Ichtyosaura alpestris) is of Least Concern (SAEFL Red List, 2005). The other four species are classified either as Vulnerable (Palmate newt, Lissotriton helveticus) or as Critically Endangered (Smooth newt, Lissotriton vulgaris; Italian crested newt, Triturus carnifex; and Great crested newt, Triturus cristatus). Interestingly, some species or subspecies are considered as Critically Endangered in some cantons, while invasive in others. For example, T. carnifex and Lissotriton v. meridionalis are threated in the canton of Ticino yet considered invasive in the canton of Geneva.

Because of their conservation status, newts are subject to constant monitoring. Most conventional methods for monitoring amphibians are based on visual surveys, where animals are counted in their environment. This can either be done using active techniques such as dip netting, seining or nocturnal counting by torchlight (all of which are effective for studying finite populations: Briggs et al. 2006, Denton et al. 2012), or passive techniques, such as traps. Since amphibians are rather timid, the use of passive techniques is known to significantly improve the efficiency of sampling (Gunzburger et al. 2007). The most effective traps will differ according to the environment in which they are set. For instance, minnow traps are appropriate for 
82 catching some amphibians during the breeding season, as they migrate to ponds and 83 generally remain in the water until the end of the spawning period. Alternatively, pitfall 84 traps and drift fences may be effective when placed on amphibians passageways, 85 when animals are migrating from their foraging to their breeding habitat and vise versa 86 (Corn et al.1990).

Recently, the analysis of environmental DNA (eDNA) has been recognized as an efficient method for the detection of amphibian species, including newts (Ficetola et al. 2008, Bálint et al. 2018, Goldberg et al. 2018, Eiler et al. 2018). The amphibian eDNA typically consists of genetic material that is released in the environment, through mucus, secretions, excretions or other pathways (Deiner et al. 2017). In the case of newts, eDNA studies have largely focused on the Great crested newt. Rees et al $(2014,2017)$ demonstrated the effectiveness of this approach for detecting that species are present, both during and outside of the breeding season. Moreover, studies have also looked at the seasonal variation in eDNA detection (Buxton et al. 2017, 2018). A further study found that the effectiveness of detection was the same using quantitative PCR (qPCR) or metabarcoding approaches (Harper et al. 2017). However, its application to other European newt species has not yet been tested.

Here, we use eDNA metabarcoding to survey communities of newts in the urban area of the Geneva canton, Switzerland. This area was chosen because of regular surveys targeting the invasive subspecies $L$. v. meridionalis, conducted by the Swiss Coordination Center for the Protection of Amphibians and Reptiles of Switzerland (KARCH-GE, http://www.karch-gr.ch). The aim of this study was to assess the effectiveness of eDNA metabarcoding compared to conventional surveys and to provide complementary data about the whole community of newts, in addition to information about the targeted invasive species. 
110 Material and Methods

111 Sampling sites $\Omega$

112 Forty-five ponds were sampled in the Geneva area, Switzerland. Most of the ponds

113 were situated in the south bank of Geneva town, in the highly urbanized area. A few

114 sites situated in the suburbs were also examined (Figure S1, Table S3). The sampling

115 campaign was part of a routine monitoring survey of newt communities, organized by

$116 \mathrm{KARCH}-\mathrm{GE}$ in April 2017 at the beginning of the newt breeding period. The

117 morphological surveys were conducted on 42 out of 45 ponds. For each pond, the

118 number of surveys performed was often limited to 1 (13 sites) but in some cases the

119 surveys were done much more frequently (10 sites), up to 100 times in the case of site

120 9. Newts were morphologically identified and counted in 25 out of 42 sites. At 17 sites

121 their abundance was estimated as low, moderate or high.

\section{DNA barcoding}

123 In order to develop newt-specific primers, 16S barcode sequences were obtained for

124 five species and subspecies present in Switzerland. One specimens of Lissotriton

125 helveticus, 4 specimens of Lissotriton vulgaris meridionalis, 2 specimens of

126 Ichthyosaura alpestris, and 2 specimens of Triturus cristatus/carnifex species complex

127 were collected in the Geneva canton, while 2 specimens of Lissotriton vulgaris were

128 collected in the canton of Neuchâtel.

129 Specimens were morphologically identified, and pieces of crest or tail were preserved

130 in ethanol and stored at $-20^{\circ} \mathrm{C}$. Tissues samples were extracted using the DNeasy®

131 Blood and Tissue kit (Qiagen, Hilden, Germany) according to the manufacturer's

132 instructions. A fragment of 16S rRNA gene was then amplified using 16sar- $L$ and

133 16sbr-H (Palumbi et al. 1991) with an initial denaturation at $95^{\circ} \mathrm{C}$ for 5 min followed by

13440 cycles of $30 \mathrm{~s}$ at $95^{\circ} \mathrm{C}, 30 \mathrm{~s}$ at $52{ }^{\circ} \mathrm{C}$ and $45 \mathrm{~s}$ at $72{ }^{\circ} \mathrm{C}$, and terminated by a final

135 elongation step of 5 minutes at $72^{\circ} \mathrm{C}$. PCR products were purified using High Pure

136 PCR Cleanup Micro Kit (Roche Kaiseraugst, Basel, Switzerland) and quantified by

137 fluorometric quantitation using Qubit 3 fluorometer (Thermo Fisher Scientific, Ma, 
138 USA). Amplicons were then sequenced on a Sanger sequencer (AB|3130xI).

139 Sequences were edited with CodonCode Aligner software v6.0.2 and analysed with

140 SeaView software version 4.6 (Gouy et al. 2010). Sequences were submitted to NCBI

141 GenBank (Benson et al. 2000) database under the accession numbers MH818456 to

142 MH818464 and MW418322 to MW418328 (Table S5).

\section{Metabarcoding primers}

145 The DNA barcode sequences obtained in this study were aligned to 72 sequences of 8 146 newt species from GenBank. New primers were designed manually, taking in

147 consideration their potential specificity to the newt species considered in this study. The

148 forward primer 16S_1121 (5'-TTTTCCGTGCAGAAGCG-3') shows a molecular

149 signature on its 3' end that appears to be shared within Salamandridae. The reverse

150 primer 16S_1378 (5'-GCGCTGTTATCCCTAGGG-3') is highly conserved among

151 metazoans. The designed primers were analyzed using Multiple Primer Analyzer online

152 tool (ThermoFisher) to check basic parameters. Specificity of the primers was first

153 checked in silico using BLAST ${ }^{\circ}$ (Altschul et al. 1990). Then, the primers were tested on

154 tissue-extracted DNA from the five newt species. To determine the resolution of newt

155 species for the amplified fragment (alignment of 271bp), a NJ tree (Saitou et al. 1987)

156 was run on 79 sequences of newt species with 1000 bootstrap replicates with algorithm

157 implemented in Seaview software version 4.6 (Gouy et al. 2010) (Figure S1).

159 Metabarcoding

160 eDNA Sampling, extraction and amplification

161 For eDNA analysis, one litre of water was collected per site in a Nalgene sterile 162 polyethylene terephthalate (PET) bottle (Thermo Fisher Scientific, Ma, USA). Bottles 163 were immediately placed into a cooler filled with ice and transported to the lab, where 164 they were stored for a few days at $-20^{\circ} \mathrm{C}$ until filtration. 
165 After thawing in the dark, $750 \mathrm{ml}$ of the water was filtered through Whatman Glass 166 microfiber filters ( $25 \mathrm{~mm}$ diameter, $0.6 \mu \mathrm{m}$ pore size) using a cleaned reusable capsule

167 (Swinnex, Millipore). Between six and 12 filters were necessary for each site

168 depending on the water turbidity. DNA on the filters was then extracted using DNeasy

169 Blood and Tissue kits (Qiagen). Filters were first incubated in the lysis buffer for 48

170 hours at $56^{\circ} \mathrm{C}$. The extraction was then performed following the manufacturer's

171 instructions, and a final elution volume of $100 \mu$ l. DNA extracts from filter replicates per

172 sites were pooled and stored at $-20^{\circ} \mathrm{C}$ until further analysis.

173 Extracted eDNA was amplified using the newly designed primers with an initial

174 denaturation at $95^{\circ} \mathrm{C}$ for $5 \mathrm{~min}$ followed by 40 cycles of $30 \mathrm{~s}$ at $95^{\circ} \mathrm{C}, 30 \mathrm{~s}$ at $52^{\circ} \mathrm{C}$

175 and $45 \mathrm{~s}$ at $72^{\circ} \mathrm{C}$, terminated by a final elongation step of 5 minutes at $72^{\circ} \mathrm{C}$. To

176 ensure multiplexing of the sample into one sequencing library, tagged primers bearing

177 eight nucleotides attached at 5' end were included in the initial PCR reaction (Esling et

178 al. 2015). Fifteen PCR replicates and one negative amplification control per sample

179 were performed and replicates were pooled for further steps. Pooled PCR products

180 were then purified using High Pure PCR Cleanup Micro Kit (Roche Kaiseraugst, Basel,

181 Switzerland), with an elution volume of $50 \mu$, and quantified using Qubit 3 fluorometer

182 (Thermo Fisher Scientific, Ma, USA). Amplified samples were pooled with

183 approximatively $10 \mathrm{ng} / \mu \mathrm{l}$ of DNA per sample for library preparation.

185 High-throughput sequencing (HTS) and data processing

186 The library was prepared using TruSeq DNA PCR-Free kit (Illumina, San Diego, USA)

187 following the provided protocol and quantified by qPCR using KAPA Library

188 Quantification Kits (Roche Kaiseraugst, Basel, Switzerland). The library was finally

189 sequenced on Illumina MiSeq System using the MiSeq Reagent Kit v2 500-cycles

190 (Illumina, San Diego, USA). The raw sequencing data are available at the Short Read

191 Archive public database under the accession SUB10388543. Raw R1 and R2 fastq

192 files for each sample were retrieved using the demultiplexer module implemented in

193 SLIM (Dufresne et al. 2019). Quality filtering, removal of chimeric sequences and the 
194 amplicon sequence variant (ASV) table were generated using DADA2 R package

195 v.1.10.1 (Callahan et al. 2017). Species occurrence represented by less than 10 reads

196 were not taken into account. For taxonomic assignment, IDTAXA function of the

197 DECIPHER R package v.2.10.2 (Wright 2016) was used with the local database used

198 for DNA barcoding and a confidence threshold of 60 . As the subspecies $L$. $v$.

199 meridionalis could not be well distinguished from $L$. vulgaris based on the IDTAXA

200 assignment, and L. vulgaris is not present in the Geneva area, all ASVs assigned to

201 the clade L. vulgaris/L. v. meridionalis were assigned to L. v. meridionalis. The

202 proportion of each taxonomic group was calculated after a BLAST analysis against the

203 GenBank database with $80 \%$ of identity to the representative ASV.

204 Results

205 Sequence data

206 In the DNA barcoding part of this study, 16 Sanger sequences of a fragment of the 16S

207 rRNA gene (about 500 to $600 \mathrm{bp}$ ) were obtained (Table S5). Phylogenetic analysis of

208 these sequences and other sequences of the related species available in the GenBank

209 showed that each species formed a supported clade clearly distinct from the other

210 species. This was confirmed by the distance tree of the short region of about $270 \mathrm{bp}$

211 selected for metabarcoding analyses (Figure S1). As shown by the tree, all clades are

212 strongly supported, except the clade formed by the subspecies $L$. $v$. meridionalis that

213 branches among other sequences of $L$. vulgaris.

215 The eDNA metabarcoding analysis was conducted on a total of 4,106,172 good-quality

216 reads ranging from 1,836 to 184,853 reads per site. The sequences were clustered into

2171028 ASVs and assigned to investigate the taxonomic composition of the amplicons

218 dataset that was obtained with the new primers. This analysis showed that $88 \%$ of the

219 reads belonged to the amphibians, followed by $6 \%$ to bacteria and $3 \%$ assigned to other

220 eukaryotes (Figure 1). Only $3 \%$ of the reads could not be assigned to any higher

221 taxonomic group. Within amphibians, the $99.9 \%$ of the sequences were assigned to 
222 newts with a high proportion of $I$. alpestris (82\%). The remaining $0.1 \%$ of the sequences 223 were assigned to the Order Anura.

\section{Metabarcoding survey of newts}

226 To investigate deeper the composition of newt populations in the-Geneva urban area, 227 the relative abundance of newt metabarcode sequences was analysed in each pond

228 (Figure 2). Raw data with the reference sequences as well as the assignments are 229 given in Table S2. The distribution of newt species in the Geneva area is illustrated in 230 Figure 3. The map shows the locations of the 45 sampling sites and provides a zoom

231 window on sites concentrated around the area where the invasive newt subspecies ( $L$.

232 v. meridionalis and T.carnifex) were first observed.

233 The most abundant newt species in our metabarcoding dataset was I. alpestris, which 234 was present at all studied sites with a proportion varying between $1 \%$ (site ROU) and 235 almost $100 \%$ (site 10 ), and reaching over $50 \%$ at 32 of the 45 sites. The second most 236 abundant newt was L. v. meridionalis, detected at $53 \%$ (24) of the 45 sites, with a 237 relative abundance reaching $95 \%$ in the case of Site 61 . However, the number of 238 reads assigned to this subspecies was small at most sites and represented by less 239 than 10 reads in 5 ponds (not visible in the Figure 2). Lissotriton helveticus and $T$. 240 carnifex were both found in 11 ponds with proportions reaching 95\% (MOU) and 50\% 241 (CHO), respectively. Sequences of $T$. cristatus were found in 7 ponds with a maximum 242 relative abundance of $57 \%$ (MAT), but in most of the ponds the number of reads 243 assigned to this species was relatively small (below 10 reads in one site).

244 According to metabarcoding data, the co-occurrence of newt species in the same 245 ponds was rather limited. There were only a few sites where four species were detected. At the vast majority of sites, only one or two species were detected.

247 Remarkably, I. alpestris shared its habitat either with L. v. meridionalis or L. helveticus, 248 although these two species were detected together at only one site (GCO). Lissotriton 249 helveticus was often detected in the same ponds as $T$. cristatus or $T$. carnifex. The fact 
250 that the two latter species are hybridizing in the Geneva area (Dufresnes et al. 2016)

251 might explain their co-occurrence at several sites.

252

253 Comparison with morphological survey

254 Metabarcoding data were compared to morphological surveys for three species (L. $V$. 255 meridionalis, I. alpestris and the hybrid T. cristatus/carnifex) that were monitored by $256 \mathrm{KARCH}-\mathrm{GE}$ during the year 2017. The total number of observed adults and larvae at 257 the 25 sites where the newts were counted was 2447 for L. v. meridionalis, 1862 for $I$. 258 alpestris and 44 for $T$. cristatus/carnifex (Table S3). In general, the number of 259 observed specimens increased with the number of surveys. No newts were observed 260 at only 6 out of the 42 sites.

261 The comparison between the morphological surveys and the metabarcoding analysis 262 regarding the presence/absence of the three newt species show that at the majority of 263 sites, when a species was detected in morphology surveys it was also present in 264 metabarcoding data (green in Figure 4). There were 19 (21 considering cases with 265 less than 10 reads) sites (blue), where a species was detected through metabarcoding 266 alone and 6 sites (red) where a species was observed in morphological surveys but 267 not in metabarcoding data. The most abundant species (I. alpestris) was detected in 268 metabarcoding data at every site, while it was missing in morphological surveys at 6 269 sites. However, both sites were investigated only once during the year. In the case of

270 L. v. meridionalis, the subspecies was observed morphologically and genetically in 9

271 (11 considering cases with less than 10 reads) ponds. The 9 sites that only showed a 272 molecular signal for this species were investigated once during the year. Finally, the

273 hybrid species $T$. cristatus/carnifex was found at 14 sites during the morphological 274 surveys and the species was abundant at 10 sites. Metabarcoding was congruent with 275 morphological observations in 6 cases ( 7 if the low number of reads are included).

276 However, it failed to detect this species at 5 sites, of which four were indicated as

277 having abundant population of this species. Conversely, two other sites $(123,129)$ 
278 showed a strong molecular signal for $T$. cristatus/carnifex, despite the fact that the 279 species was not physically observed there.

\section{Discussion}

282 Our study confirms the effectiveness of eDNA metabarcoding to detect newts in 283 aquatic environments (Harper et al. 2017) and to monitor freshwater pond fauna more 284 widely (Harper et al. 2019). Compared to the conventional surveys, metabarcoding 285 confirmed the presence of two species (I. alpestris and L. v. meridionalis) at all sites where they were observed. Moreover, their DNA traces were detected at an additional 15 sites where both species were not observed, suggesting that metabarcoding is more sensitive and could help to overcome the limitations of the observational approach, which is usually based on a single observation conducted during a particular season. Interestingly, visits to some sites (i.e. site 96) a year after our samples were collected confirmed the presence of the species indicated by eDNA (KARCH-GE, pers. 292 comm).

293 There were only six cases in our study where a species was observed but not detected

294 in metabarcoding data and all these cases concerned the crested newt complex ( $T$. 295 cristatus/carnifex). Compared to the Alpine newt (I. alpestris) and L. v. meridionalis, 296 the crested newts were less commonly observed (14 out of 42 sites). They have been detected at only eight of these sites (including one detection based on a single read). This lack of congruence between conventional observation and metabarcoding data could be considered as a species-specific artefact, e.g. due to a bias of our primers. However, this interpretation seems unlikely, as our primers fit perfectly to the two Triturus species, both in silico and tested on tissue samples. Interestingly, in 5 out of 6 sites where the crested newt was observed but not detected by eDNA, the specimens were not counted. Further studies of these sites might be needed to confirm whether the species was really present there. 
305 The congruence observed in the presence/absence data was partly confirmed by

306 abundance data. Similar agreement has been reported in several fish eDNA studies,

307 where the number of fish eDNA reads was in rough congruence with the abundance of

308 species (Lacoursière-Roussel et al. 2016, Fukaya et al. 2020). In our study, large

309 numbers of metabarcoding reads often corresponded to large number of specimens

310 for the two most common newts (. alpestris and L. V. meridionalis). The few cases

311 where these numbers were not in agreement could be explained by the fact that the

312 number of observations was inconsistent between sites, with some sites being

313 inspected more often than others. Moreover, the observations were not conducted at

314 the same time as the eDNA sampling. Another explanation could be the patchiness of

315 newt eDNA distribution in the ponds, which might not always be encompassed the

316 relatively limited water sampling. Although we did not expect a strong correlation

317 between the number of reads and the abundance of specimens, our data suggest that

318 this might be possible, at least for some species.

319 The main advantage of eDNA metabarcoding illustrated by our study is its capacity to

320 survey the whole community of newts rather than a single species, the latter being the

321 case when the qPCR-based approach is adopted (Rees et al. 2017, Harper et al. 2018).

322 By using newt-specific primers we were able to obtain an inventory of all newt species

323 present in the area as well as to investigate their distribution. First of all, we confirmed

324 that the Alpine newt is the dominant species in the Geneva urban area, as it is in

325 Switzerland as a whole. The DNA of this species was found at practically all sites,

326 sometimes as a unique species, but more often in conjunction with other newt species.

327 This might suggest the exceptional adaptation of this species to the life in the cities,

328 where numerous small garden ponds offer excellent conditions for breeding (De Troyer

329 et al. 2020).

330 Another species that also seems to adapt easily to urban conditions is $L$. $v$. meridionalis.

331 This subspecies, native to Italy, is considered as invasive in Geneva, where it was first

332 observed in 1978 (Jaussi 1979). As shown by our data, L. v. meridionalis often shares

333 the breeding ponds with the Alpine newt, but it does not seem to outcompete it. In fact,

334 we did not find any site that was inhabited exclusively by L. v. meridionalis. The 
335 subspecies was also found sharing sites with crested newts ( $T$. cristatus/carnifex) but 336 only on three occasions at the periphery of its range, which might indicate that its

337 interactions with other species are not totally neutral. According to our study, the

338 distribution of L. v. meridionalis is restricted to the area delimited by southern bank of

339 Lake Geneva, the Rhone river and the Arve river. Its presence at two sites (GCO and

340 MAT) situated across the rivers Arve and Rhône (Figure 3) might be explained by

341 anthropic dispersal, which is common in urban areas. Hence, further monitoring of the

342 expansion of this subspecies is very important, especially in view of its possible

343 negative impact on other newts living in the area.

344 Globally, an encouraging result of this study is that almost all species of newts living in

345 Switzerland could be detected in the small and highly urbanized area of Geneva canton.

346 This finding confirms that urban areas are shelters for a wide diversity of wildlife that are

347 adapted to its particular conditions. In this context, eDNA metabarcoding offers an

348 efficient and reliable tool to survey this urban wildlife. Until now, metabarcoding has

349 been mainly applied to monitoring urban fauna in terrestrial environments (Hoffmann et

350 al. 2018, Potter et al. 2019). Its use to monitor urban aquatic biodiversity was relatively

351 limited and focused on microbiota (Bagley et al. 2019, Hervé et al. 2018, Hervé and

352 Lopez 2020) and the detection of invasive species (Clusa et al. 2017), despite the fact

353 that numerous human-made water bodies are situated in private gardens and parks.

354 Since access to these properties is often limited, asking their owners to collect water

355 eDNA samples might be easier to organize than conventional observations. The non-

356 invasive collection of large amount of data for routine monitoring has obvious practical

357 advantages, and would also contribute to raising interest in urban biodiversity and

358 motivating residents to protect it.

\section{Conclusions}

361 Our study confirms the usefulness of eDNA metabarcoding for monitoring aquatic

362 biodiversity in urban areas. Taking the newts as an example, we show that the urban

363 ponds are inhabited by a rich community of species. We found a good congruence 
364 between eDNA data and conventional observations. Yet, the detection of some newts'

365 species seems easier than the others. Further studies are needed to evaluate the

366 impact of abundant species on the detection of rare species in eDNA datasets. This and

367 other issues related to eDNA data interpretation can only be solved by more regular

368 eDNA surveys, which will hopefully follow this precursor study.

\section{Acknowledgements}

370 The authors are thankful to KARCH-GE Team: Emeline Chapron, Lucien Guignet, as

371 well as to the owners of examined ponds and the authorities. We also thank to the three

372 anonymous reviewers for very thoughtful comments and to Prof. Andrew Gooday (NOC,

373 Southampton) for correcting the English. 
375

376

377

378

379

380

381

382

383

384

385

386

387

388

389

390

391

392

393

394

395

396

397

398

399

400

401

\section{References}

Altschul, S. F., Gish, W., Miller, W., Myers, E. W., \& Lipman, D. J. (1990). Basic local alignment search tool. Journal of molecular biology, 215(3), 403-410. DOI: 10.1016/S0022-2836(05)80360-2

Bagley, M., Pilgrim, E., Knapp, M., Yoder, C., Santo Domingo, J., \& Banerji, A. (2019). High-throughput environmental DNA analysis informs a biological assessment of an urban stream. Ecological indicators, 104, 378-389. DOI: 10.1016/j.ecolind.2019.04.088.

Bálint, M., Nowak, C., Márton, O., Pauls, S. U., Wittwer, C., Aramayo, J. L., ... \& Jansen, M. (2018). Accuracy, limitations and cost efficiency of eDNA-based community survey in tropical frogs. Molecular Ecology Resources, 18(6), 1415-1426. DOI: 10.1111/1755-0998.12934.

Benson, D. A., Cavanaugh, M., Clark, K., Karsch-Mizrachi, I., Lipman, D. J., Ostell, J., \& Sayers, E. W. (2012). GenBank. Nucleic acids research, 41(D1), D36-D42. DOI:

10.1093/nar/gks1195

Bormpoudakis, D., Foster, J., Gent, T., Griffiths, R. A., Russell, L., Starnes, T., ... \& Wlikinson, J. (2016). Developing models to estimate the occurrence in the English countryside of Great Crested Newts, a protected species under the Habitats Directive.

Briggs, I., Rannap, R., Pappel, P., Bibelriether, F., \& Päivärinta, A. (2006). Monitoring methods for the great crested newt Triturus cristatus. Protection of Triturus cristatus in the Eastern Baltic region" LIFE2004NAT/EE/000070 Action A, 2. 
402 Buxton, A. S., Groombridge, J. J., Zakaria, N. B., \& Griffiths, R. A. (2017). Seasonal

403 variation in environmental DNA in relation to population size and environmental

404 factors. Scientific reports, 7(1), 1-9. DOI: 10.1038/srep46294.

405

406

Callahan, B. J., McMurdie, P. J., \& Holmes, S. P. (2017). Exact sequence variants

407

should replace operational taxonomic units in marker-gene data analysis. The ISME

408

journal, 11(12), 2639-2643. DOI: 10.1038/ismej.2017.119.

409

410 Clavero, M., \& García-Berthou, E. (2005). Invasive species are a leading cause of

411 animal extinctions. Trends in ecology \& evolution, 20(3), 110.

412

413 Clusa, L., Miralles, L., Basanta, A., Escot, C., \& Garcia-Vazquez, E. (2017). eDNA for

414 detection of five highly invasive molluscs. A case study in urban rivers from the Iberian

415 Peninsula. PloS one, 12(11). DOI: 10.1371/journal.pone.0188126.

416

417 Corn, P. S., \& Bury, R. B. (1990). Sampling methods for terrestrial amphibians and

418 reptiles. Gen. Tech. Rep. PNW-GTR-256. Portland, OR: US Department of Agriculture,

419 Forest Service, Pacific Northwest Research Station. 34 p, 256. DOI: 10.2737/PNW-

420 GTR-256.

421

422 De Troyer, N., Forio, M. A. E., Roels, K., De Meester, L., Lemmens, P., Declerck, S. A., 423 ... \& Goethals, P. (2020). Key management rules for agricultural alpine newt breeding 424 ponds based on habitat suitability models. Global Ecology and Conservation, e01086. 425 DOI: 10.1016/j.gecco.2020.e01086.

427 Deiner, K., Bik, H. M., Mächler, E., Seymour, M., Lacoursière-Roussel, A., Altermatt, F., 428 ... \& Bernatchez, L. (2017). Environmental DNA metabarcoding: Transforming how we 429 survey animal and plant communities. Molecular ecology, 26(21), 5872-5895. DOI:

$430 \quad 10.1111 / \mathrm{mec} .14350$. 
432 Denton, R. D., \& Richter, S. C. (2012). A quantitative comparison of two common 433 amphibian sampling techniques for wetlands. Herpetological Review, 43(1), 44-47.

434 DOI: 10.1163/157075309X12470350858433.

435 Dufresnes, C., Pellet, J., Bettinelli-Riccardi, S., Thiébaud, J., Perrin, N., \& Fumagalli, L. 436 (2016). Massive genetic introgression in threatened northern crested newts (Triturus 437 cristatus) by an invasive congener (T. carnifex) in Western Switzerland. Conservation 438 Genetics, 17(4), 839-846. DOI: 10.1007/s10592-016-0825-6.

439

440 Dufresne, Y., Lejzerowicz, F., Perret-Gentil, L. A., Pawlowski, J., \& Cordier, T. (2019).

441 SLIM: a flexible web application for the reproducible processing of environmental DNA 442 metabarcoding data. BMC bioinformatics, 20(1), 1-6. DOI: 10.1186/s12859-019-2663-2. 443

444 Edgar, P., \& Bird, D. R. (2006). Action plan for the conservation of the crested newt 445 Triturus cristatus species complex in Europe. Council of the European Union, 446 Strassbourg, Germany, 1-33.

447

448 Eiler, A., Löfgren, A., Hjerne, O., Nordén, S., \& Saetre, P. (2018). Environmental DNA 449 (eDNA) detects the pool frog (Pelophylax lessonae) at times when traditional monitoring 450 methods are insensitive. Scientific reports, 8(1), 1-9. DOI: 10.1038/s41598-018-237404515.

452

453 English Nature (2001). Great crested newt mitigation guidelines. English Nature, 454 Peterborough

455

456 Esling, P., Lejzerowicz, F., \& Pawlowski, J. (2015). Accurate multiplexing and filtering 457 for high-throughput amplicon-sequencing. Nucleic acids research, 43(5), 2513-2524. 458 DOI: 10.1093/nar/gkv107. 459

460 Esri. "Study area and location of surveyed ponds". Scale Not Given. "World Imagery". 461 October 6, 2020. "Publication URL". 
462

463 Esri. "Study area and location of surveyed ponds". Scale Not Given. "World

464 Topographic Map". October 6, 2020. "Publication URL".

465

466

467 Ficetola, G. F., Miaud, C., Pompanon, F., \& Taberlet, P. (2008). Species detection using

468 environmental DNA from water samples. Biology letters, 4(4), 423-425. DOI:

469 10.1098/rsbl.2008.0118.

470

471 Fukaya, K., Murakami, H., Yoon, S., Minami, K., Osada, Y., Yamamoto, S., ... \&

472 Kondoh, M. (2020). Estimating fish population abundance by integrating quantitative

473 data on environmental DNA and hydrodynamic modelling. Molecular ecology. DOI:

474 10.1111/mec.15530.

475

476 Goldberg, C. S., Strickler, K. M., \& Fremier, A. K. (2018). Degradation and dispersion

477 limit environmental DNA detection of rare amphibians in wetlands: Increasing efficacy of

478 sampling designs. Science of the Total Environment, 633, 695-703. DOI:

479 10.1016/j.scitotenv.2018.02.295.

480

481 Gouy, M., Guindon, S., \& Gascuel, O. (2010). SeaView version 4: a multiplatform

482 graphical user interface for sequence alignment and phylogenetic tree

483 building. Molecular biology and evolution, 27(2), 221-224. DOI:

484 10.1093/molbev/msp259.

485

486 Gunzburger, M. (2007). Evaluation of seven aquatic sampling methods for amphibians

487 and other aquatic fauna. Applied Herpetology, 4(1), 47-63. DOI:

$488 \quad 10.1163 / 157075407779766750$.

489

490 Harper, L. R., Lawson Handley, L., Hahn, C., Boonham, N., Rees, H. C., Gough, K. C., 491 ... \& Hänfling, B. (2018). Needle in a haystack? A comparison of eDNA metabarcoding 
492 and targeted qPCR for detection of the great crested newt (Triturus cristatus). Ecology

493 and evolution, 8(12), 6330-6341. DOI: 10.1002/ece3.4013.

494 Harper, L. R., Buxton, A. S., Rees, H. C., Bruce, K., Brys, R., Halfmaerten, D., ... \&

495 Hänfling, B. (2019). Prospects and challenges of environmental DNA (eDNA) monitoring

496 in freshwater ponds. Hydrobiologia, 826(1), 25-41. DOI: 10.1007/s10750-018-3750-5.

497

498

Hayes, T. B., Falso, P., Gallipeau, S., \& Stice, M. (2010). The cause of global

499 amphibian declines: a developmental endocrinologist's perspective. Journal of Experimental Biology, 213(6), 921-933. DOI: 10.1242/jeb.040865.

501

502

Hervé, V., Leroy, B., Pires, A. D. S., \& Lopez, P. J. (2018). Aquatic urban ecology at the 503 scale of a capital: community structure and interactions in street gutters. The ISME 504 journal, 12(1), 253-266. DOI: 10.1038/ismej.2017.166.

Hervé, V., \& Lopez, P. J. (2020). Analysis of interdomain taxonomic patterns in urban street mats. Environmental Microbiology, 22(4), 1280-1293. DOI: 10.1111/14622920.14933.

509

Hoffmann, C., Merkel, K., Sachse, A., Rodríguez, P., Leendertz, F. H., \&

Calvignac-Spencer, S. (2018). Blow flies as urban wildlife sensors. Molecular ecology

512 resources, 18(3), 502-510. DOI: 10.1111/1755-0998.12754.

513

514 Jaussi M. Contribution à l'étude des Batraciens du Bassin genevois, Diplôme de

515 Biologie, Université de Genève, 1979. 149 pp.

516

517 Lacoursière-Roussel, A., Rosabal, M., \& Bernatchez, L. (2016). Estimating fish

518 abundance and biomass from eDNA concentrations: variability among capture methods

519 and environmental conditions. Molecular ecology resources, 16(6), 1401-1414.

520 DOI: $10.1111 / 1755-0998.12522$. 
522 Palumbi, S. R., Martin, A. P., Romano, S., McMillan, W., Stice, L. and Grabowski, G.

523 (1991). The simple fool's guide to PCR. University of Hawaii

524

525 Potter, C., De Vere, N., Jones, L. E., Ford, C. R., Hegarty, M. J., Hodder, K. H., ... \&

526 Franklin, E. L. (2019). Pollen metabarcoding reveals broad and species-specific

527 resource use by urban bees. PeerJ, 7, e5999. DOI: 10.7717/peerj.5999.

528

529

Rees, H. C., Baker, C. A., Gardner, D. S., Maddison, B. C., \& Gough, K. C. (2017). The

530

detection of great crested newts year round via environmental DNA analysis. BMC

531

Research Notes, 10(1), 327. DOI: 10.1186/s13104-017-2657-y.

532

533 Rees, H. C., Bishop, K., Middleditch, D. J., Patmore, J. R., Maddison, B. C., \& Gough,

534 K. C. (2014). The application of eDNA for monitoring of the Great Crested Newt in the

535 UK. Ecology and Evolution, 4(21), 4023-4032. DOI: 10.1002/ece3.1272.

536

537

Rouse, J. D., Bishop, C. A., \& Struger, J. (1999). Nitrogen pollution: an assessment of

538 its threat to amphibian survival. Environmental health perspectives, 107(10), 799-803.

539

540

Saitou, N., \& Nei, M. (1987). The neighbor-joining method: a new method for

541 reconstructing phylogenetic trees. Molecular biology and evolution, 4(4), 406-425.

542 DOI:10.1093/oxfordjournals.molbev.a040454

543

544 Schmidt, B., Zumbach, S. (2005). Liste Rouge des amphibiens menacés en Suisse.

545 Office fédéral de l'environnement, des forêts et du paysage (OFEFP).

546

547 Temple, H. J., \& Cox, N. A. (2009). European red list of amphibians (No. 333.957094 548 E89). 
550 Van Rooij, P., Martel, A., Haesebrouck, F., \& Pasmans, F. (2015). Amphibian

551 chytridiomycosis: a review with focus on fungus-host interactions. Veterinary 552 research, 46(1), 1-22.

553

554 Wright, E. S. (2016). Using DECIPHER v2. 0 to analyze big biological sequence data in 555 R. $R$ Journal, 8(1).

556

557

558

559

560 


\section{Figure 1}

Proportion of major taxonomic groups amplified by the set of new $16 \mathrm{~S}$ primers designed in this study.

Species assignments were performed using BLAST ${ }^{\circledR}$ against the GenBank database.

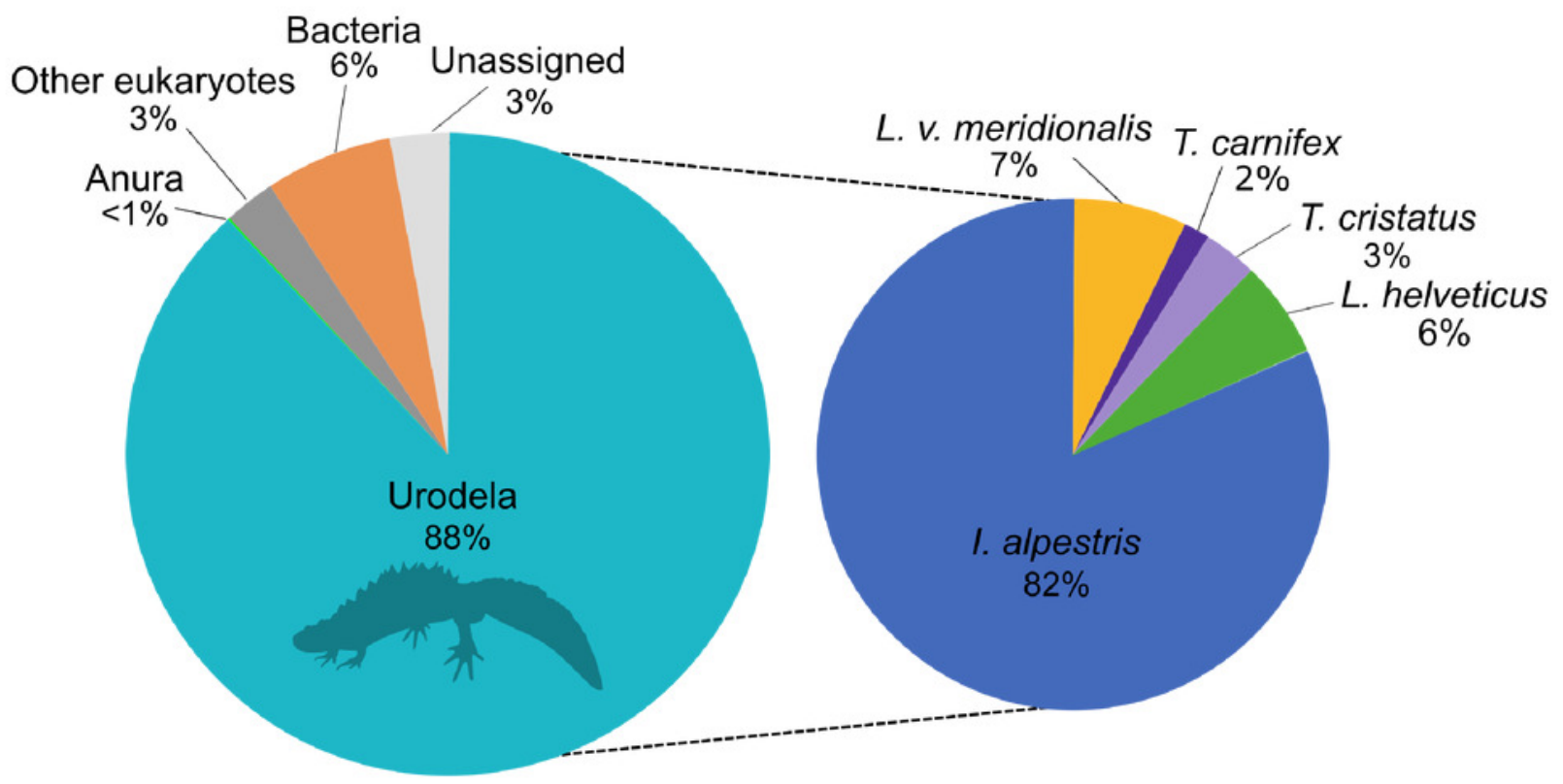


Figure 2

Relative abundance of newts' species across 45 ponds based on metabarcoding data.

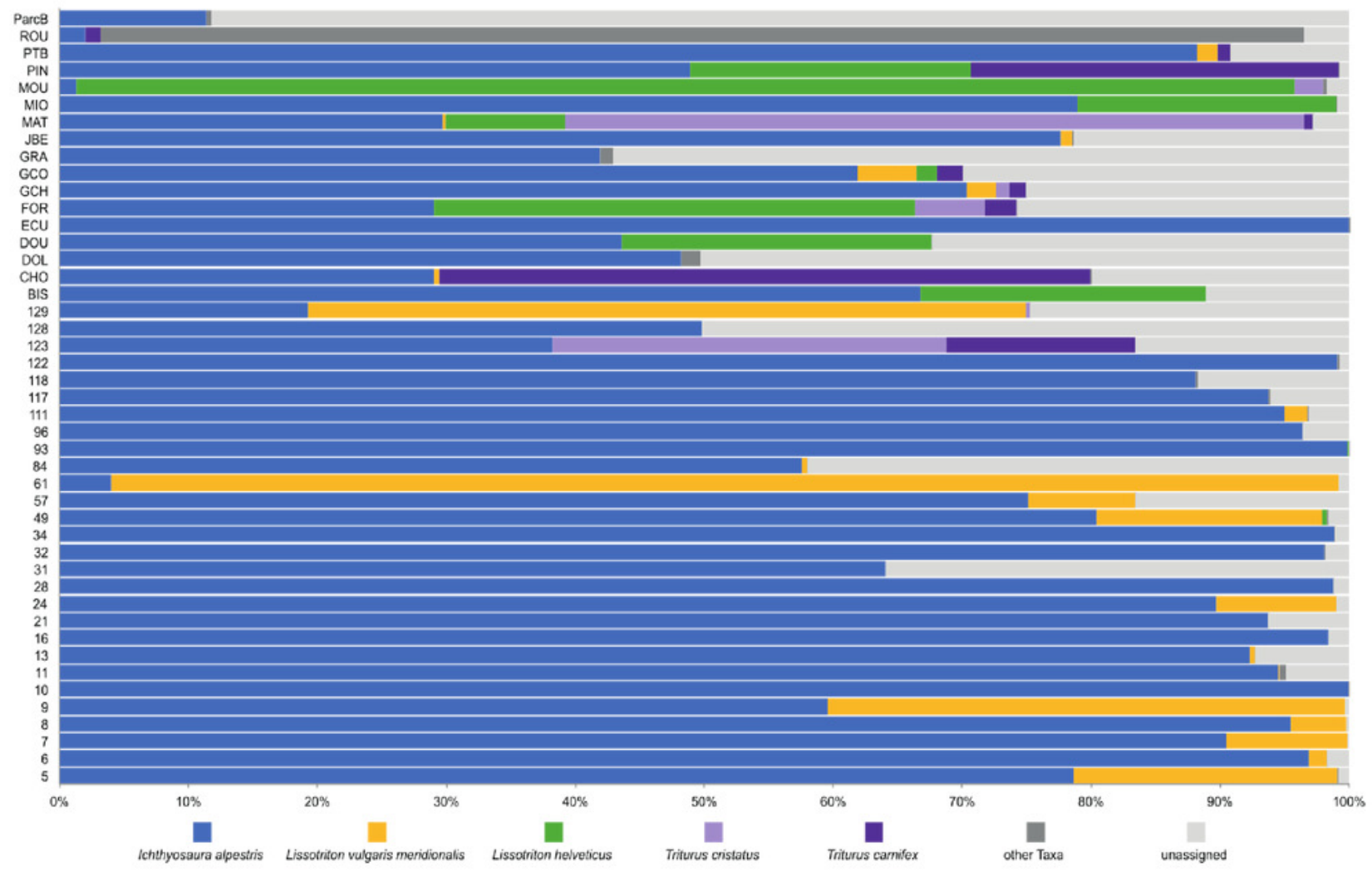




\section{Figure 3}

Study area and location of surveyed ponds.

Map displaying samples location in Geneva urban area. Pie charts colors correspond to the presence/absence of I. alpestris (blue), L. v. meridionalis (orange), L. helveticus (green) and T. cristatus/carnifex hybrid (purple). Map created with ArcGIS Pro on the base of the World Imagery and World Topographic Map basemaps.

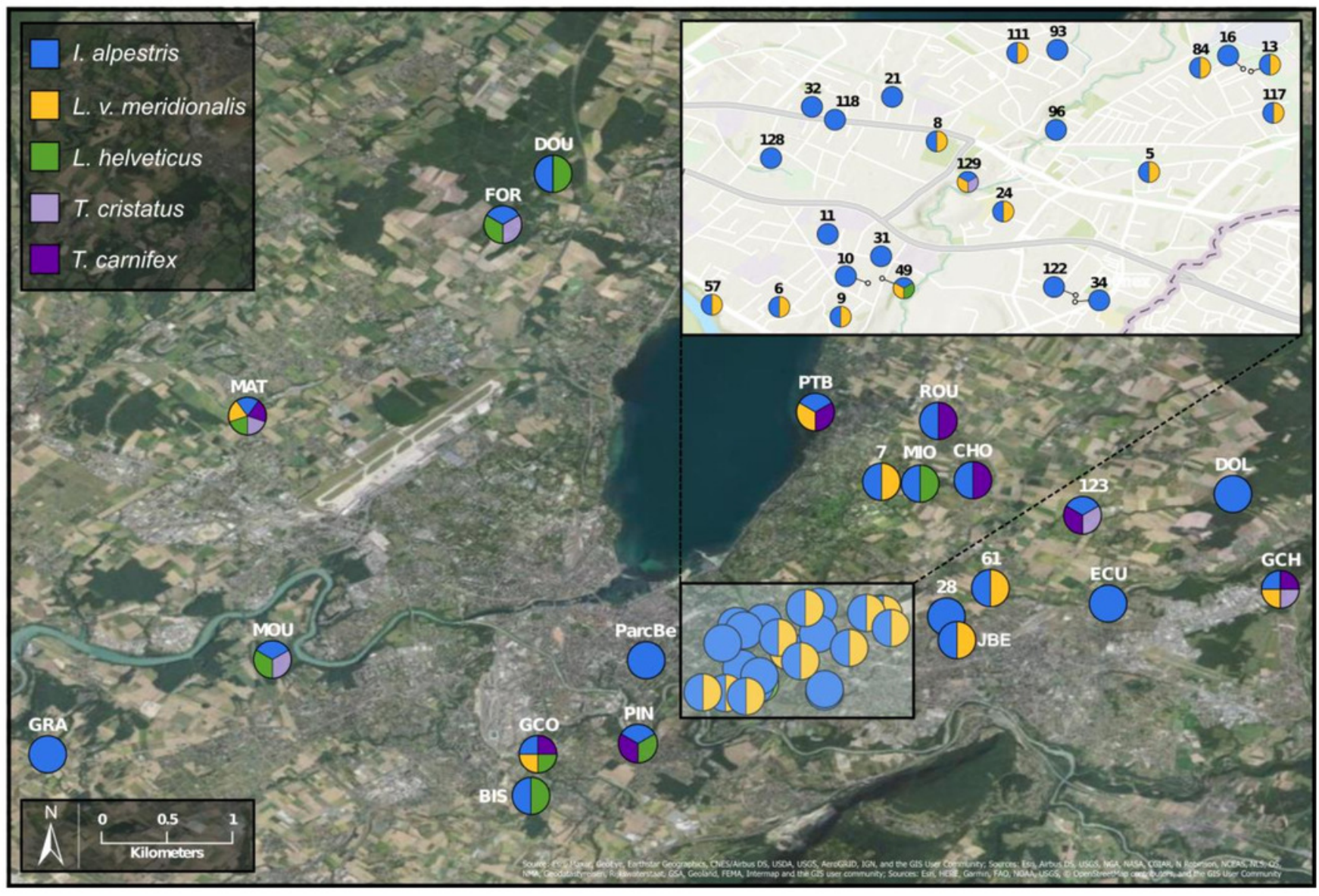




\section{Figure 4}

Congruence table of the morphological and molecular presence of species across 42 ponds.

Red color indicates presence in the morphological dataset only. Blue color indicates presence in the molecular dataset only. Green color corresponds to presence in both morphological and molecular dataset. Light green and light blue colors indicate that number of molecular reads were below 10 . Single reads were ignored in this plot. Samples that were not investigated for morphological survey (samples 61, 84 and 128) were removed from the plot.

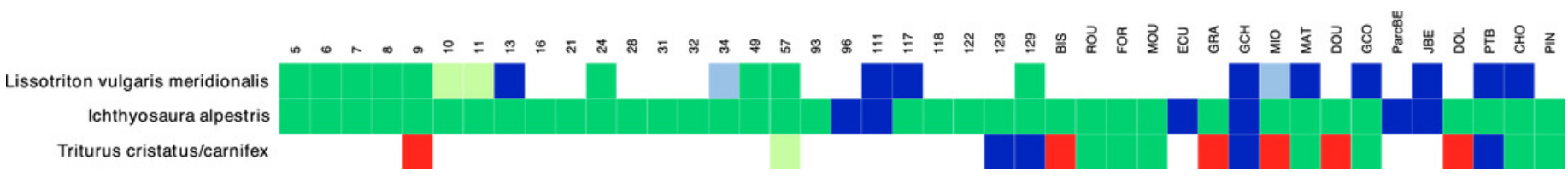

